The sessions are generally very well evaluated: feedback comments from recent sessions include the following: "the carer was very inspiring and it was helpful to hear first-hand experience"..."very upsetting at times but have taken a lot from the experience nonetheless"..."especially enjoyed the talk regarding spirituality"

It has always proved important to discuss the sessions with the Interprofessional Learning Co-ordinator in the School of Social Work at the University to see if there have been any changes to the core teaching programme, in order that we can ensure that the sessions are covering new ground for the students and enhancing their learning about hospice care, which we believe is a life lesson for all.

\section{P49 WILLEN HOSPICE - CHANGING THE FACE OF MANDATORY TRAINING THROUGH BLENDED LEARNING}

Marilyn David, Annette Hart. Willen Hospice, Milton Keynes, United Kingdom

10.1136/bmjspcare-2013-000591.71

Title Changing the face of mandatory training through blended learning.

Background New medical director observed that staff did not demonstrate an understanding of Mental Capacity Act (MCA).

MCA provides protection for both patients and staff.

Evidence of training required for CQINS.

Aims and objectives

- By linking theory to practice, enhances staff knowledge.

- By using mental capacity we were promoting patient choice as central to specialist palliative care.

- Key functional skills embedded into mandatory training.

Approach used Practice Development Lead Nurse formed a multi-professional group to review how MCA training could be facilitated. The group decided to train staff who were in daily contact with patients. This included clinical and non-clinical staff from reception, housekeeping and catering.

Training was divided into two parts:

Part 1; included key facts related to the act. Staff completed an online training session. Online quiz was used to assess staffs understanding of the theory of the MCA.

Part two; Staff attended a workshop and small groups worked through different scenarios exploring how key points of the MCA works in day-to-day practice. Workshop facilitators were from different disciplines to provide breadth of insight.

Outcomes

- Learning was measurable. An $80 \%$ pass mark was required to progress to part two of the training. Feedback was obtained from the workshops.

- A competent hospice workforce with the MCA embedded into practice.

- Staff demonstrating how to empower patients to make choices.

- Innovative approach to hospice learning.

Staff feedback "It affects everyone and all staff has a responsibility"

"Mental capacity is part of everyday care"

"We should accept people's decisions even if we don't agree"

"Eccentric or odd decisions are okay"

Application to Hospice Practice Our education reflects the broadening horizons of palliative care. Developing, equipping and preparing staff for the new challenges ahead.
P50 END OF LIFE CARE (EOLC) TRAINING FOR SOCIAL CARE PROVIDERS IN DEVON

David Rainbow, Liz Gibbons, Michelle Pryor. Hospiscare Exeter, Exeter, Uk

\subsection{6/bmjspcare-2013-000591.72}

This two year Community Pilot in end of life care training for social care providers is a collaborative venture between Devon local authority and Hospiscare.

Aims

1. To identify the EOLC training needs of domiciliary care workers.

2. To identify obstacles and inequalities in the provision of domiciliary EOLC in Devon.

Our Approach Three towns were identified as pilot sites. Twenty-four domiciliary care agencies's were approached and asked for information relating to:

1. Staff numbers/turnover

2. Hours of contracted EOL/palliative care

3. Their training needs

4. Barriers in accessing training

Hospiscare community teams, the Hospiscare education team, and primary care nurse managers were also interviewed.

Findings We received a $92 \%$ response rate from Domiciliary Care Agency's employing just over a 1000 staff.

Analysis of results indicated a need for an introductory level one day programme, In improving the carer's knowledge, skills and confidence in EOLC.

In addition managers identified gaps in their knowledge relating to their role in EOLC. A manager level one day programme was designed around, the "6 Steps" National Programme.

To date:

Between 05/03/12 and 27/03/13, 400 care workers have attended the Introductory programme 100 senior staff have attended the Managers Programme.

$97 \%$ of attendees rated the programme as very good or excellent.

The programme has been extended to the whole of Devon, and those working in residential care.

A train the trainer programme is set for release in June. Enabling senior staff to deliver the introductory programme.

Challenges:

In times of substantial service redesign building good relationships and effective communication links with social care providers is key. It is important to make a non-statutory programme attractive through course timing, content and pricing. Sustainability is dependent on facilitating others to deliver the Programme (s), and by connecting with the real concerns and systems of work in grass roots social care.

\section{P51 SIX STEPS + WIDENING THE ACCESS TO GOOD EOL CARE}

Gail Wilson, Paula Hine, Judith Talbot. St lukes Hospice, Plymouth, England

\subsection{6/bmispcare-2013-000591.73}

The Six Steps + project aimed to create a local hospice accredited EOL quality kite mark to support local health and social care providers build their knowledge, skills and confidence in delivering EOL care. The project built on previous work by the North West and includes additional assessments and workshops 
on dementia and learning disabilities. The project was supported by Burdett Nursing Trust and local commissioners who wanted to see improved standards of EOL care.

The Six Steps + programme has been running for the last 12 months and currently has 66 organisations and 131 individuals registered. The programme has been very successful and has delivered real service improvements eg the last post death audit (412 deaths), demonstrated that $42 \%$ of individuals who died had an Advance Care Plan in place and the number of inappropriate hospitals admissions fell from $40 \%$ to $23 \%$.

The project truly promotes integrated working. The hospice equality mark is now published in the local authority's online public directory. Organisations stated they wanted to have a local quality mark linked to the local hospice which families recognise. The EOL Link Forum is pivotal to service integration as well as being a vehicle for ongoing audit and monitoring end of life outcomes.

The programme does not provide any educational credit therefore Skills for Care was approached to accredit the programme. This resulted in a national mapping tool being created to map the Six Steps to the new Quality Credit Framework EOL qualifications.

The next step for the project is to create a train the trainer programme to help others implement Six Steps + in their area. Hospices cannot provide all EOL care and they have an important role in enabling providers in their communities to deliver good quality equitable EOL care for all.

\section{P52 QUALITY END OF LIFE CARE FOR ALL (QELCA ${ }^{\odot}$ )}

Liz Bryan', Marie Cooper', Anita Hayes'; 'St Christopher's Hospice, Sydenham, United Kingdom, ${ }^{2}$ Help the Hospices, ${ }^{3}$ NHS Improving Quality (formally National End of Life Care Programme (NEOLCP))

\subsection{6/bmjspcare-2013-000591.74}

The Department of Health has concluded that the non-specialist workforce needs to develop the necessary attitudes and skills in order to deliver consistently high quality care for people approaching the end of life and is looking for beacons of best practice in relation to practice development initiatives $(\mathrm{DoH}$, 2008).

St Christopher's Hospice has designed a training programme which not only role-models end of life care to the participants but equips and empowers them to deliver better care to patients on their return to practice. QELCA $\odot$ was designed to be delivered by hospice nurses to nurses working in hospitals. Teams of acute nurse clinical managers from the same department spend 5 days based at the hospice in small groups of three or four. Using the hospice setting as a learning resource, nurses are offered a first-hand experience of observing and being alongside specialist nurses as they care for patients at the end of life. In addition to this practice experience the 5-day programme combines classroom discussion and reflection facilitated by experienced specialist palliative care nurses. The programme then continues with six months facilitated Action Learning Sets (ALS) so that action plans for self, team and organisation, formulated by the participants on the final day of their hospice experience, can be supported in practice and learning from the programme consolidated.

In partnership with St Christopher's and Help the Hospices, the National End of Life Care Programme (NEoLCP), through the Transform Programme (NEoLCP, 2013), piloted QELCA ${ }^{\odot}$ across 17 sites. 21 hospices were involved and a total of 137 acute nurses attended the QELCA $^{\odot}$ programme. Evaluation data were collected at four stages across the pilot timeline using mixed methods comprising, survey questionnaires, semi-structured questionnaires and focus groups. A report outlined the findings and made recommendations for the further development of the programme.

\section{P53 QUALITY END OF LIFE CARE FOR ALL [QELCA] LEEDS}

Laura Speight, Steve Lawman; St Gemma's Hospice, Leeds, England

\subsection{6/bmjspcare-2013-000591.75}

Introduction St Gemma's Hospice and Leeds teaching hospitals trust are involved in a national end of life care programme's pilot. This is an education initiative called 'Quality End of Life Care for All’ [QELCA] developed by St Christopher's hospice. Aims

- Share expertise of Hospice care with nurses working in a variety of settings where End Of Life Care [EOLC] was being provided.

- Empowerment of generalist nurses to make a difference in practice, providing EOLC.

- Address with nurses issues of anxiety, fear, and lack of insight/self-awareness when providing EOLC.

- Equip nurses to remain in meaningful emotional contact with patients/relatives whilst preserving professional integrity.

- Prevention of emotional exhaustion and risk of 'burn out'.

\section{Methods}

- 5 days placement at St Gemma's Hospice.

- Combination of facilitated classroom learning and practical experience. [IPU, Community, Day services.]

- Reflect on learning and formulate action plan for priorities for change.

- Action plan is supported by facilitated action learning [AL] over six sessions.

Results

- Positive relationships/ networks between acute and hospice staff.

- Constructive comments made regarding EOLC provision in different clinical areas.

- Each QELCA candidate focusses on something to change/ implement within clinical practice based on Hospice experience.

- During AL sessions, progress discussed/ action plans made. Changes occurred, with management support.

Discussion Attendance and feedback from the course is so far very positive, candidates enjoyed being in the different environment. AL sets not well attended therefore criteria could be changed for future courses. Results from AL are positive showing that changes had been implemented and worked in practice.

Conclusion/ Future recommendations Since the introduction of the DoH's End of life care strategy 2008, there has been a focus on patients' wishes at end of life especially on Preferred Place of Care, [PPC]. Courses such as QELCA, enable healthcare professionals to expand their knowledge in such a specialist area and provide such care through a process of innovation and change. 